\title{
De la pesca, las islas y la basura: Notas etnográficas en el archipiélago de pescadores artesanales de Puerto Gala, región de Aysen, Chile
}

\author{
ON FISHING, ISLANDS AND GARBAGE: ETHNOGRAPHIC NOTES IN THE \\ ARCHIPELAGO OF ARTISANAL FISHERMEN OF PUERTO GALA, AYSEN REGION, \\ CHILE
}

\section{SOBRE PESCA, ILHAS E LIXO: NOTAS ETNOGRÁFICAS NO ARQUIPÉLAGO DE PESCADORES ARTESANAIS DE PUERTO GALA, REGIÃO DE AYSEN, CHILE}

\author{
Rodrigo Díaz Plá*1 \\ rdiazpla@gmail.com
}

Recibido: 24/4/2020 Aceptado: 11/9/2020

\begin{abstract}
Resumen
Este artículo, condensa las notas etnográficas y reflexiones del trabajo de campo desarrollado durante la segunda mitad de la década de 2000 en el aislado archipiélago de Puerto Gala, en el litoral de la región de Aysen en el sur austral de Chile. Estas notas y reflexiones giran en relación a la observación sobre la problemática de la pesca artesanal, la insularidad y la contaminación provocada por la basura, una problemática poco abordada desde el contexto institucional y que hoy en día, es una preocupación para las comunidades insulares en Chile. El artículo comienza contextualizando respecto a la pesca artesanal en Chile, dando una visión general al lector que le permita entender de mejor manera el sistema pesquero en estas latitudes. Luego, se despliega una descripción sobre Puerto Gala: su historia, sus particularidades y la relación intrínseca entre los que habitan estos parajes con el mar. Finalmente, se reflexiona sobre la basura y las prácticas observadas en el territorio.
\end{abstract}

Palabras Clave: etnografía, notas de campo, pesca artesanal, educación ambiental, basura.

\begin{abstract}
This article condenses the ethnographic notes and reflections of the field work carried out during the second half of the $2000 \mathrm{~s}$ in the isolated archipelago of Puerto Gala, on the coast of the Aysen region in southern Chile. These notes and reflections revolve in relation to the observation about the problem of artisanal fishing, insularity and pollution caused by garbage, a problem little addressed from the institutional context and that today is a concern for island communities in Chile.

The article begins by contextualizing the artisanal fishing in Chile, giving the reader a general vision that allows him to better understand the fishing system in these latitudes. Then, a description of Puerto Gala is displayed: its history, its peculiarities and the intrinsic relationship between those who inhabit these places with the sea. Finally, it reflects on the garbage and the practices observed in the territory.
\end{abstract}

Keywords: ethnography, field notes, artisanal fishing, environmental education, garbage

\footnotetext{
1 * Centro de Investigación/Acción de la Pesca Artesanal y las Sociedades Costeras, Chile
}

Tekoporá ${ }^{\circledR}$. Centro Universitario de la Región Este. Universidad de la República (C) Díaz Plá (2020)

Este es un artículo de Acceso Abierto distribuido bajo licencia Creative Commons (CC BY NC 4.0) 


\section{Resumo}

Este artigo condensa as notas etnográficas e as reflexões do trabalho de campo realizado durante a segunda metade dos anos 2000 no isolado arquipélago de Puerto Gala, na costa da região de Aysen, no sul do Chile. Essas notas e reflexões giram em torno da observação sobre o problema da pesca artesanal, a insularidade e a poluição causada pelo lixo, um problema pouco abordado no contexto institucional e que hoje é uma preocupação das comunidades insulares no. Chile. 0 artigo começa contextualizando a pesca artesanal no Chile, dando ao leitor uma visão geral que lhe permitirá compreender melhor o sistema pesqueiro nessas latitudes. Em seguida, é apresentada uma descrição de Puerto Gala: sua história, suas peculiaridades e a relação intrínseca entre aqueles que habitam estes lugares com o mar. Por fim, reflete sobre o lixo e as práticas observadas no território.

Palavras chaves: etnografia, notas de campo, pesca artesanal, educação ambiental, lixo

\section{Introducción}

\section{Pesca Artesanal en Chile}

En la larga y angosta franja de tierra que ocupa el espacio terrestre de nuestro país, se desarrolla una multiplicidad de actividades ligadas al sector marítimo. A estas actividades las denominaremos de borde y altamar. Ya sea en el norte o en el sur, la actividad pesquera, artesanal e industrial; la actividad mariscadora y la recolectora de algas, se desarrolla de manera extensiva e intensiva, logrando ser incluso en algunos lugares la actividad económica predominante.

Si bien es cierto, la cantidad y el tipo de recursos marinos varía dependiendo de zonas climáticas y geográficas específicas, lo cual provoca que se desarrollen distintos tipos de tradiciones culturales entorno a la actividad pesquera, el ser humano, desde los primeros asentamientos en este largo territorio, ha configurado el mar como fuente de subsistencia. Este hecho nos da pie para señalar la importancia de la actividad pesquera en Chile, sobre todo en localidades o regiones en contacto permanente con el mar.

Sin embargo este espacio ocupado adquiere formas y matices diferentes, reconocibles tanto en la literatura arqueológica como también en estudios realizados en la actualidad. Los aparejos de pesca, las embarcaciones, las formas organizativas e incluso las festividades en torno a la actividad, varían exclusivamente de la zona en la cual se desarrolla la actividad pesquera, y también depende del recurso el cual se desea extraer.

Tal como en la mayoría de los países en que la actividad pesquera es parte importante de la economía nacional, en Chile se cuenta con distintas instituciones ligadas a la actividad pesquera. Una de estas instituciones es el Servicio Nacional de Pesca (SERNAPESCA), el cual funciona como ente regulador de la actividad pesquera industrial y artesanal. Para SERNAPESCA, la pesca artesanal es "la actividad pesquera extractiva realizada por personas naturales en forma personal, directa y habitual y, en el caso de las áreas de manejo, por personas jurídicas compuestas exclusivamente por pescadores artesanales, inscritos como tales. Un pescador artesanal es aquél que se desempeña como patrón o tripulante en una embarcación artesanal. Si éste es dueño de hasta dos embarcaciones será armador artesanal; si su actividad principal es la extracción de mariscos, será mariscador y si realiza recolección y secado de algas será alguero. Dichas categorías de pescador artesanal no son excluyentes entre sí, por lo que una persona puede ser calificada y actuar simultánea o sucesivamente en dos o más de ellas, siempre que todas se ejerciten en la misma Región" (SERNAPESCA, 2018). En relación a estas especialidades, podemos señalar que son aplicables a todas las zonas pesqueras del país sin 
distinción, por lo que la variabilidad de la ocupación va a depender de condicionantes como el tipo de recurso extraído, la geografía del lugar, el contexto histórico-cultural, etc. No debemos olvidar que existe una variedad de oficios ligados a la pesca artesanal que no están tipificados, como por ejemplo los carpinteros de ribera o encarnadoras/es.

Luego del golpe militar ocurrido en Chile el año 1973, el gobierno de facto a partir de la apertura a los mercados internacionales y nuevos tratados económicos principalmente con Asia y U.S.A., impulsó políticas de exportación de los recursos extraídos en distintos territorios del país (Calderón et al., 2013). Los recursos marinos no fueron la excepción, y progresivamente aquellos recursos que habían presentado un estable ciclo productivo y comercial a lo largo de su historia, como el loco (Concholepas concholepas) y el erizo (Loxechinus albus) por poner un ejemplo, explotaron en diversos booms económicos que provocaron procesos socioeconómicos de alto alcance en nuestro país. A Muchos de estos procesos se les denominaron fiebres (fiebre del loco, fiebre de la merluza austral, fiebre de las algas, etc.), y como tales tuvieron expresiones diversas de carácter no tan sólo económico, sino que también implicancias en términos socioculturales, políticos y territoriales. Para el año 1989, la sobreexplotación del loco llegó a su punto límite. La fiebre del loco había provocado no sólo desplazamientos que tenían efectos directos en las poblaciones costeras, sino que también un sinnúmero de naufragios documentados en la prensa de la época y conflictos locales derivados de estos movimientos migracionales.

El sector pesquero artesanal, desde su ordenamiento a comienzos de la década de 1990 con la implantación de la LGPA, ha experimentado profundas transformaciones que han afectado de manera directa sus formas de vida (Brinck, Díaz Plá, Morales y Marín, 2011). Junto con esto, se han generado altos grados de vulnerabilidad de las poblaciones que realizan esta actividad (INE, 2008), sumándose además a un alto número de pescadores artesanales de la región que no participan ni reciben los beneficios que otorga el Estado para quienes detentan estas condiciones (Ascui, 2015).

Complementando este escenario para la pesca artesanal, algunos estudios reseñan respecto a las perspectivas futuras por parte de comunidades costeras. Y es que a pesar de una notable adaptación a las transformaciones ecológicas, sociales, políticas y económicas, las poblaciones de pescadores artesanales ven desde un punto de vista negativo el futuro en el desarrollo de su actividad (Brinck, et al., 2011, Luna, 2009, Alcalá y Camargo, 2012). Esta mirada negativa ha podido ser observada a partir de la desintegración de la actividad, o como señala Galo Luna (2009):

"existe una perspectiva negativa en la población sobre el futuro de las pequeñas economías, viéndose afectadas en la renovación y crecimiento demográfico. Son los sectores jóvenes de las localidades quienes están más permeables a los procesos de proletarización asociado a razones de expectativas y calidad de vida, mientras que para el caso de los adultos, quienes denotan un mayor apego a las tradiciones y valores culturales de las localidades, demuestran una mayor resistencia a la proletarización atisbando como salida al problema la semicapitalización" (Luna, 2009).

Este mismo autor destaca que frente a estos procesos de transformación socioeconómica, los pescadores artesanales buscan "optar por figuras empresariales familiares o cooperativizadas. Desde las economías de subsistencia las opciones colectivas son mejor recibidas que las iniciativas privadas, porque visualizan posibilidades de iniciar procesos conjuntos con garantías de mantener un cultura e identidad local" (Luna, 2009). En este sentido, la resistencia cultural se realiza a través de formas colectivas o asociativas para la mantención identitaria, particularmente a "la noción de economías vinculadas a un tipo particular de territorio y actividad productiva colectiva y tradicional” (Luna, 2009). 
Durante los últimos treinta años los recursos pesqueros de nuestro país se han visto reducidos drásticamente a causa de la presión ejercida por grupos humanos dedicados a su extracción principalmente para la exportación de éstos mismos hacia nuevos mercados principalmente asiáticos y europeos (Gelcich et al., 2010, Stotz, 1997, Brinck, et al., 2011). Este panorama ha generado una crisis gradual y sistemática en las poblaciones de pescadores artesanales que habitan nuestras costas, profundizando condiciones de vulnerabilidad y riesgo social (Alcalá, 1992). Sumado a esto, los sistemas ecológicos que sustentan la producción y economía de estos grupos se han visto impactados por diversos factores, generando de esta manera una problemática que requiere de una visión holística y sistémica.

\section{Las islas en el sur del mundo}

Puerto Gala, islas de colonizadores y viajeros. Pescadores y buscadores de la vida, en un tiempo no tan lejano, se embarcaron en una de las mayores aventuras de sus existencias, y se instalaron en estas remotas regiones australes, en donde el clima es inclemente, y la soledad en un comienzo se hacía insostenible. Nada hacía presagiar el futuro venidero. El día a día era la vida entera, y en este se dejaba está tratando de llevar el sustento a la "rancha", aquella vivienda de plástico y madera, frágilmente construida, pero con una base de sueños que soportaban la débil estructura. Ni el viento pudo con muchos de estos soñadores, que hoy por hoy y tal como ellos mismos confidencian, "aun seguimos haciendo patria en tierras tan lejanas".

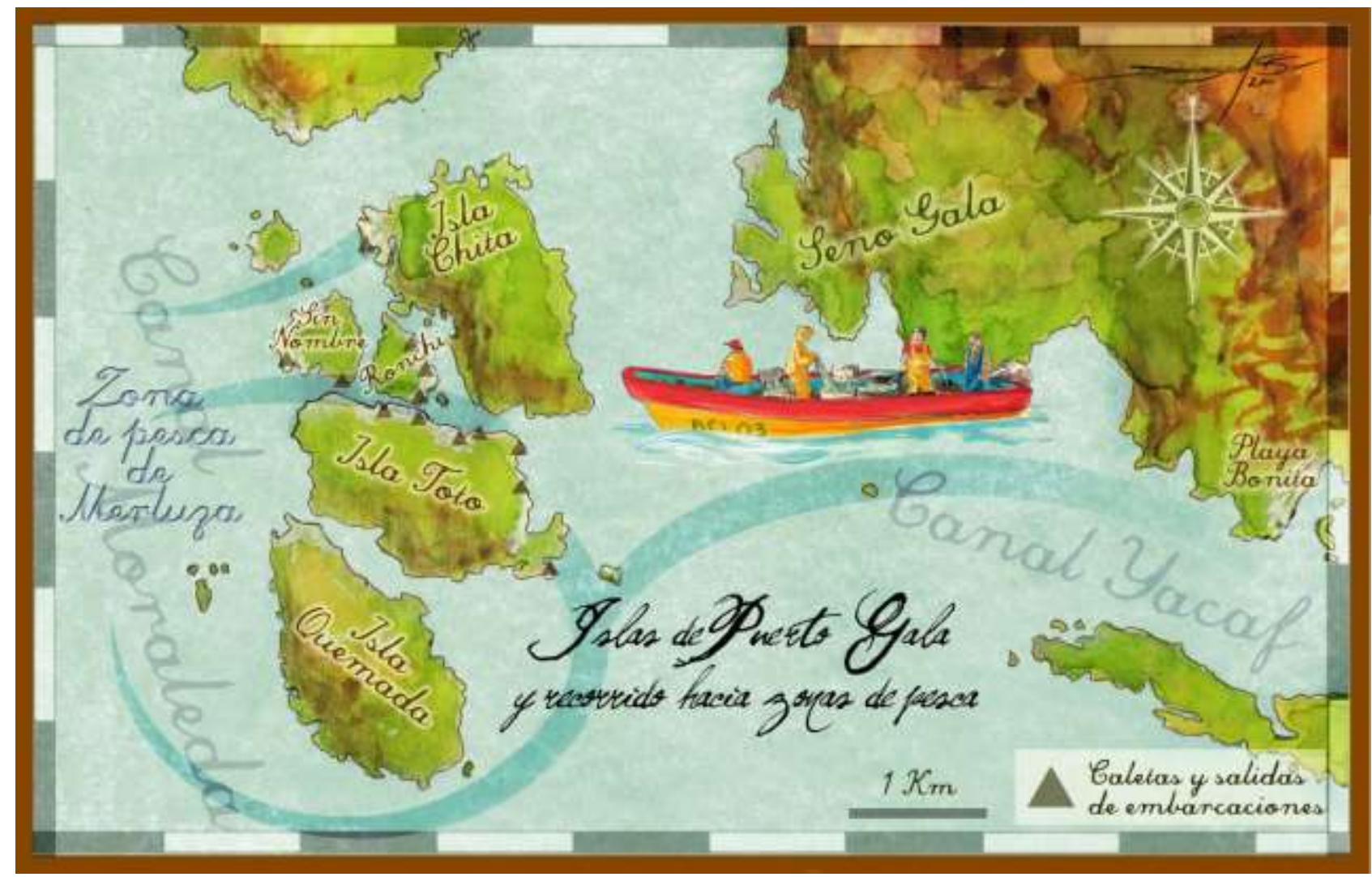

Figura 1. Mapa 01 Mapa de Puerto Gala. Ilustración. 2011. Autor: Diego Artigas (Brinck, Díaz Plá, Morales y Marín, 2011).

El llamado "Grupo Gala" es un conjunto de cinco pequeñas islas que se encuentran en 
permanente contacto debido a su cercanía. Esto se potencia además porque dos de estas islas se encuentran conectadas por una pasarela, y también por el mar, la "avenida" más transitada de esta localidad. Las islas que componen Puerto Gala son Isla Toto, Isla Gala, Isla Ronchi, Isla Núñez e Isla Chita. De estas cinco islas, cuatro se encuentran habitadas (I. Ronchi, I. Toto, I. Núñez e Isla Chita). Todas ellas también sirven para la extracción de otros recursos, principalmente la madera.

Al igual que la mayoría de las islas de esta región, su actividad económica principal es la pesca. Sin ahondar mucho en esta temática ya que lo mencionaremos y profundizaremos más adelante, cabe destacar que Puerto Gala es una localidad reciente. Su fecha de fundación oficial fue el día 21 de Agosto de 1999, convirtiéndose así en el último pueblo fundado del siglo XX. La razón de esta fundación tardía, es que su poblamiento masivo y permanente se comenzó a dar entre los años 1985 y 1987, progresivamente instalándose mayor población inmigrante en busca de nuevas expectativas de vida y además debido a lo que se le llama "La fiebre de la merluza austral" (Brinck, Díaz Plá, Morales y Marín, 2011).

En una manera de contextualizar la experiencia de trabajo de campo y realizar un acercamiento a la localidad de Puerto Gala, esta sección pretende dar a conocer los aspectos más importantes de esta zona del país, tanto como su historia, su geografía, las principales actividades económicas, y por supuesto algunos datos relevantes para esta investigación.

\section{Ubicación en el país y en la región}

Las islas, accidentes geográficos identificables en todos los rincones del mundo, son particulares campos de acción de la antropología hoy en día. Primero que todo, existe un reconocimiento generalizado a la distinción entre isla y continente. La isla es un lugar imaginariamente limitado, en donde la continuidad elemental (me refiero a los dos elementos constitutivos de la superficie terrestre, y por lo tanto que más inciden en el asentamiento humano como lo son el agua y la tierra) se trunca, ya que en este caso especifico el agua genera "limites" definidos. Esta visión, generalizada y extendida tanto en geógrafos, geólogos y otros estudiosos de la superficie terrestre, es la que se impone en las culturas continentales. Las islas siempre han sido motivos de observación y exotismo, como lugares propios en donde se puede desarrollar tanto una cultura local perdida en la historia, hasta dinosaurios o experimentos científicos . Este límite elemental, genera que se imagine un mundo especial y único, encerrado y sin movilidad, en donde la evolución cultural de esa locación depende solamente de los hechos sociales que en ella ocurran, sin pensar siquiera en el contacto cultural como un factor incidente en el desarrollo de tal o cual sociedad (Terrell y Gosden, 1997). Sin embargo, el panorama ha ido variando, y las experiencias de trabajo de campo antropológico han llevado a reflexiones como las de Miguel Chapanoff (Chapanoff, 2001), quien señala el espacio marino como un lugar de relaciones e interacciones, y sobre todo en el contexto insular, definiéndolo como maritorio. Esto, si lo aplicamos específicamente a la región de Aysen, lo podemos entender en su contexto cotidiano: el mar y los angostos canales que se forman entre las pequeñas islas del sur de Chile se transforman en verdaderas avenidas, por donde los habitantes en sus lanchones y botes navegan día a día, de un lado a otro, ya sea en busca del sustento económico y/o por razones diversas. Este hecho, se complementa con que, al igual que en otras islas de los canales del sur de Chile, Puerto Gala no cuenta con calles ni veredas en tierra, sino que más bien sus islas se encuentran unidas por pasarelas sobre las cuales no existe un tráfico de población demasiado denso. El ubicar a las islas más allá de las barreras del entendimiento habitual es un primer paso para poder situar geográficamente a Puerto Gala y sus alrededores, ya que sin entender esta ubicación lógica, el reconocimiento de su condición de insularidad no sería comprendido 
en su totalidad.

Puerto Gala, al igual que muchas de las islas de los canales australes de Chile, es un rincón desconocido para la mayoría de los habitantes de este país. Si bien es cierto el cine y la televisión han realizado algunas producciones en la zona , lo que acercaría simbólicamente la región y la localidad a los centros urbanos en donde se concentra la mayor cantidad de población en Chile, para muchos es, aún en el siglo XXI, un lugar lejano y enigmático. Lo cierto es que la realidad dista mucho de esta creencia popular. Puerto Gala está ubicado en un lugar estratégicamente ideal para la realización de la actividad pesquera, lo cual permite así una permanente movilidad y flujo no tan solo de personas, sino además de distintos tipos de mercancías hacia distintos puntos del país, como también hacia el extranjero. Y es que a pesar de su lejanía de grandes ciudades, el archipiélago de Gala se encuentra permanentemente ligado a los mercados internacionales y al trato con compradores extranjeros, sumando a esto la constante relación

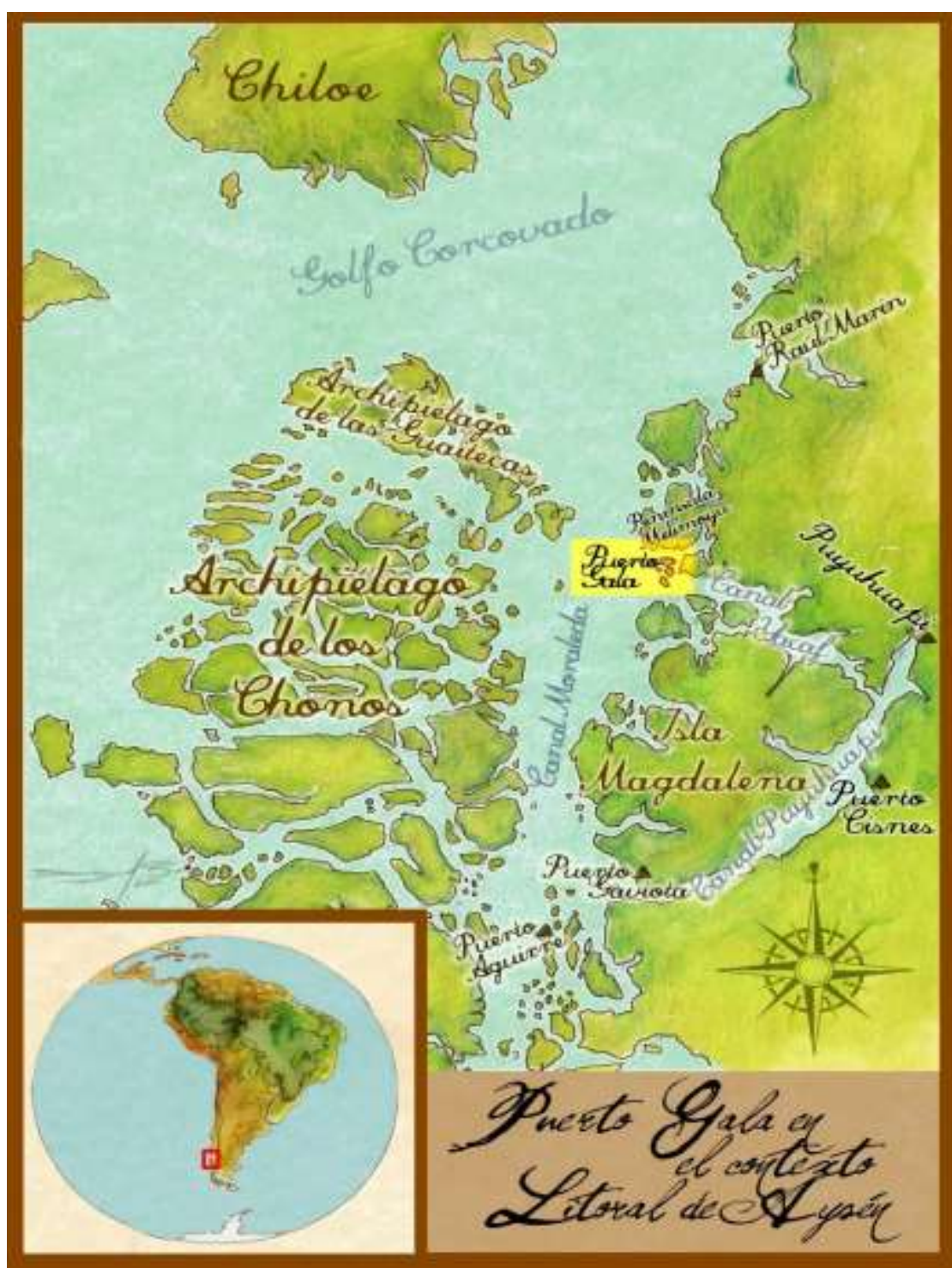
que tienen con el Estado y las empresas privadas exportadoras. En esta misma línea, desde una perspectiva más bien teórica y etnográfica, el antropólogo Frederick Eriksen nos señala que la insularidad es una constante "lucha contra el aislamiento", puesto que la isla como unidad social, cultural y económica requiere del permanente contacto para su subsistencia (Eriksen, 1993). Para Brinck y Morales, la insularidad es una condición "que no se agota en lo geográfico" (Brinck y Morales, 2007), sino que esa misma condición permite el flujo constante de elementos tanto materiales como culturales con aquellos límites externos impuestos por la geografía. En este sentido, Puerto Gala se constituye en sí como una experiencia no de aislamiento, sino más bien como forma de conexión con el mundo y la región.

Figura 02. Ubicación de Puerto Gala. Ubicación de Puerto Gala. Ilustración. Autor: Diego Artigas. (Brinck et al., 2011). 
Como bien hemos descrito anteriormente, nuestra localidad estudiada es un conjunto de islas que se encuentran en la región de Aysen, y que se encuentran exactamente ubicadas al sur del paralelo 44으, entre los canales australes de Jacaf y Moraleda. Para llegar a ella se hace solo a través de vía marítima, en viaje desde Puerto Chacabuco desde el sur, y/o desde Quellón por el norte. La extenuante experiencia de viajar 20 horas desde Chiloé en una barcaza (la "Alejandrina") que cuenta con mínimas condiciones de comodidad para sus pasajeros, es sencillamente un detalle al encontrarse con paisajes tan maravillosos. En el trayecto de la "Alejandrina" hacia Puerto Gala, no solo se puede vislumbrar la maravillosa riqueza natural de las islas, los fiordos, los canales o los volcanes imponentes como el Melimoyu; sino también una gran cantidad de fauna marina tales como toninas overas, delfines chilenos, cachalotes, ballenas y lobos de mar.

La barcaza posee dos ambientes para instalarse a discreción: un sector interior, el cual se encuentra totalmente colapsado por la cantidad de gente que intenta dormir y acomodarse en algún rincón. Este sector posee mesas, que muchas veces sirven de camas. El segundo ambiente es la parte exterior de la barcaza, y que se encuentra en un nivel superior. Este, no cuenta con ningún tipo de comodidades, y se encuentra abierto al aire libre. Existe un techo que proporciona protección relativa frente a la lluvia. Tal como el sector interior, este ambiente se encuentra por lo general colapsado.

La mayoría de los pasajeros que viajan en la barcaza son residentes de las localidades aledañas a Puerto Gala (Melinka, Raúl Marín, Melimoyu, Cisnes, Chacabuco, Puerto Gaviota, etc.), y muchos pasajeros, en conversaciones que se sostienen en el viaje, señalan que se encuentran acostumbrados a este largo trayecto.

Al llegar a Puerto Gala luego de las comentadas 20 horas de viaje, se puede apreciar a lo lejos las casas prácticamente colgando desde las pequeñas salientes de roca hacia el mar. Una gran cantidad de botes a motor espera en el agua la llegada de la barcaza, que además de traer personas, trae provisiones para los pocos almacenes de la localidad. También hay una gran cantidad de gente en tierra esperando: mujeres, niños, jóvenes y hombres, familias completas.

En el plano político-administrativo, Puerto Gala pertenece a la comuna de Puerto Cisnes, una de las comunas más grandes de la región de Aysen. Su lugar en la región es, al igual que otras islas, particularmente estratégico para la pesca artesanal, debido a que las especies se desplazan por los canales, instalándose en las aguas interiores, que poseen menor cantidad de oleaje y facilita la labor en embarcaciones pequeñas, que son las que poseen los habitantes de esta localidad.

\section{Geografía, vegetación y fauna}

Una de las características distintivas de la XI región son la cantidad de islas y canales que la trazan de norte a sur y de este a oeste. Estas particularidades marcan la geografía del lugar, y por lo tanto también determinan el eco-sistema, formando así espacios de grandes riquezas naturales y bellos paisajes. 


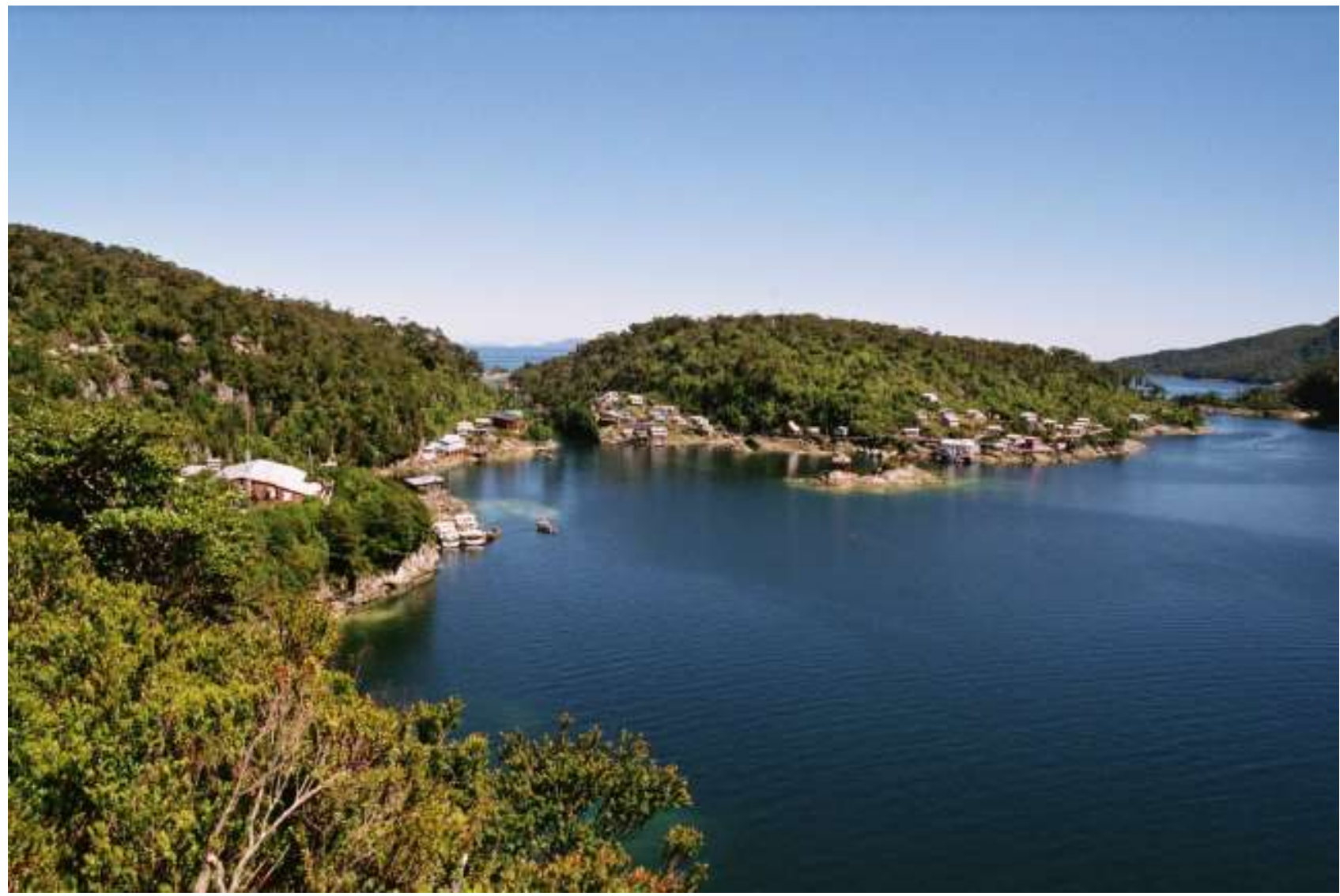

Figura 3. Panorámica de Puerto Gala. Autor: Rodrigo Díaz Plá. (Brinck et al., 2011)

En Puerto Gala, las islas que componen el pequeño grupo insular, poseen características geográficas compartidas. Todas sin distinción cuentan con pequeñas pendientes hacia el mar en el sector habitado y pronunciados cortes en piedras y pendientes en ciertos sectores. Además cuentan con algunos intervalos pequeños en los que encontramos pequeñas playas. Las rocas, que de tanto en tanto aparecen en el paisaje, son grandes y macizas, y moldean el paisaje a tal punto que las pasarelas tienen que adaptarse a este medio rocoso. La vegetación es abundante y densa, encontrando árboles tales como la Luma (Amormyrtus luma), Tineo (Weinmannia), Canelo (Drimys winteri), Coigües (Nothofagus Donbeyi, Nothofagus Betuloides), Tepa (Laurelia philipiana), entre otros. La Luma es el árbol quizás más representativo, pues su madera se caracteriza por ser densa y dura, la que sirve para todo tipo de construcciones, y como fuente importante de combustible para calefaccionar los hogares. Una de las fuentes de ingresos extras para los habitantes de Puerto Gala son las actividades forestales. Existe el relato oral generalizado sobre la existencia de una antigua industria maderera, la cual se vino abajo por la ausencia de mercados, hace aproximadamente 30 años atrás.

La fauna presente en Puerto Gala es muy diversa. Si bien es cierto la fauna marina es mucho más representativa por encontrarse en el espacio de mayor amplitud en relación a las islas, de igual manera existen especies terrestres, sobretodo aves, que ocupan un lugar en el ecosistema isleño. De la fauna marina podemos señalar la existencia de Lobos marinos (Otaria flavescens), los cuales transitan por los canales en busca de alimento, que sería por lo general restos de carnada y peces como la merluza austral. Este animal convive con el ser humano en 
una relación contradictoria: mientras su presencia demuestra la existencia de una gran cantidad peces y una rica biodiversidad, en la faena pesquera el animal se vuelve un riesgo vital para el pescador. Al intentar atrapar las carnadas enganchadas al espinel, el lobo tira de este hacia el fondo marino, provocando que en muchas oportunidades los anzuelos se claven en las manos del pescador lanzándolo al agua y luego arrastrado al fondo del mar por el animal. Este hecho provoca que este animal sea categorizado como "uno de los peores enemigos del pescador artesanal de Puerto Gala".

\section{Población y vivienda}

Al ser un conjunto de pequeñas islas con una pequeña cantidad de habitantes en cada una de ellas, Puerto Gala se configura como un pequeño caserío. Si bien es cierto se puede comprobar la existencia de pequeños "centros" más poblados que otros sectores, la realidad es que en general las casas se encuentran de manera dispersa por casi todas las islas del archipiélago de Gala.

Las viviendas son esencialmente de madera, teniendo todas la misma estructura y distribución espacial dentro de ellas, salvo algunas excepciones de viviendas que se encuentran alejadas de los centros más densamente habitados. Su material de forrado es el latón, que protege de la lluvia, la cual se presenta casi los 365 días del año. El techo también es del mismo material. Todas poseen baños químicos incorporados a las casas, ya que la ausencia de alcantarillados no permite tener desagüe. Estos baños forman parte de un proyecto de desarrollo local que busca modernizar las viviendas y mejorar la calidad de vida. La intervención del Estado en materia de infraestructura y servicios básicos también se hizo presente. Es así por ejemplo que se llegó a implementar un generador que otorga energía eléctrica. Este se activa desde las inmediaciones del gimnasio otorgando energía eléctrica a toda la localidad desde las 18:00 a las 00:00 hrs. El cobro se realiza a través del almacén de "Aravena" en Caleta Puyuhuapi, y este se hace en relación al uso y cantidad que cada vivienda le da a la energía eléctrica. Otro de los aspectos importantes a destacar y que son coincidentes con la intervención estatal es la construcción de pasarelas que recorren todas las islas, conectándolas unas con otras.

\section{El antes, el ahora y ¿el después?}

Hablar de Puerto Gala es hablar de su historia reciente y su historia lejana. Gran tarea se nos presenta, al indagar en una historia llena de sucesos y transformaciones en el seno de una localidad pesquera. Hacer una revisión desde los tiempos de la conquista de estos canales por parte de aquellos pescadores aventureros que buscaban no solo el recurso, sino también una cantidad indescifrable de sueños y aspiraciones, hasta aquellos que ya hoy son parte incólume de la identidad galense. Muchas veces aquellos sueños que surgieron a comienzos del asentamiento se vieron truncados, al filo de una navaja o de una tormenta en alta mar, pero así se constituyó la historia de Puerto Gala, a punta de esfuerzo y sacrificio, muerte y leyenda, pesca y miseria. Es así que haremos un breve paso por los tiempos mozos de esta localidad, en su formación, en los tiempos de "la ley del más fuerte" (como muchos nos señalaron) en el boom merluzero austral; hasta llegar a la actualidad, en donde cada día se intenta construir un pueblo, una identidad galense, con todas las cargas que esto podría representar. 


\section{Historia pasada: la llegada de los cazadores de la merluza austral}

Son muchos los relatos que se pueden recoger a partir de las experiencias vividas en las islas de Puerto Gala. En esta oralidad es en la que hoy descansa la construcción de una memoria colectiva, que da vida y forma a la identidad galense propiamente tal, y que constituyen por lo demás estas notas.

Con la primera aproximación a la comunidad de Puerto Gala del Núcleo de Instigación de la Realidad Insular en estos parajes en el año 2006, se logró recabar información importantísima con respecto a los primeros asentamientos y viviendas, sobre como llevaban la vida en esos tiempos sus primeros habitantes, costumbres, fiestas, conflictos y percepciones. Estas se fueron complementando con apreciaciones recabadas en las posteriores visitas, en donde los relatos, y tal como lo esperábamos, se contradecían, sacando a la luz nuevos conflictos que, contrapuestos con aquellas percepciones del pasado, nos remiten a distintas tensiones identitarias que finalmente van construyendo una imagen en común de la historia de Puerto Gala.

Brinck y Morales nos hablan de un proceso continuo y progresivo de sedentarización en la zona (Brinck y Morales, 2007). En los años 80 y principios de los 90, el paisaje era radicalmente diferente al de hoy en día. Se habla de la existencia de miles de personas trabajando en la pesca, y además de una gran cantidad de sectores de "arranchamiento" en la zona (alrededores de la isla Magdalena principalmente), esto motivado por la movilidad de la merluza austral. Ladiseo Subiabre, pescador artesanal, señala que:

"Aquí había creo que fácilmente sobre dos mil habitantes, cosa que ahora hay como trescientos cuando están todos. Por ser, aquí en Casa de Piedra había gente, en Puerto Gato, en Cholgeros, en Islas Bajas, en Quincheros, en Ballena, Filomena, toda la zona por abajo.

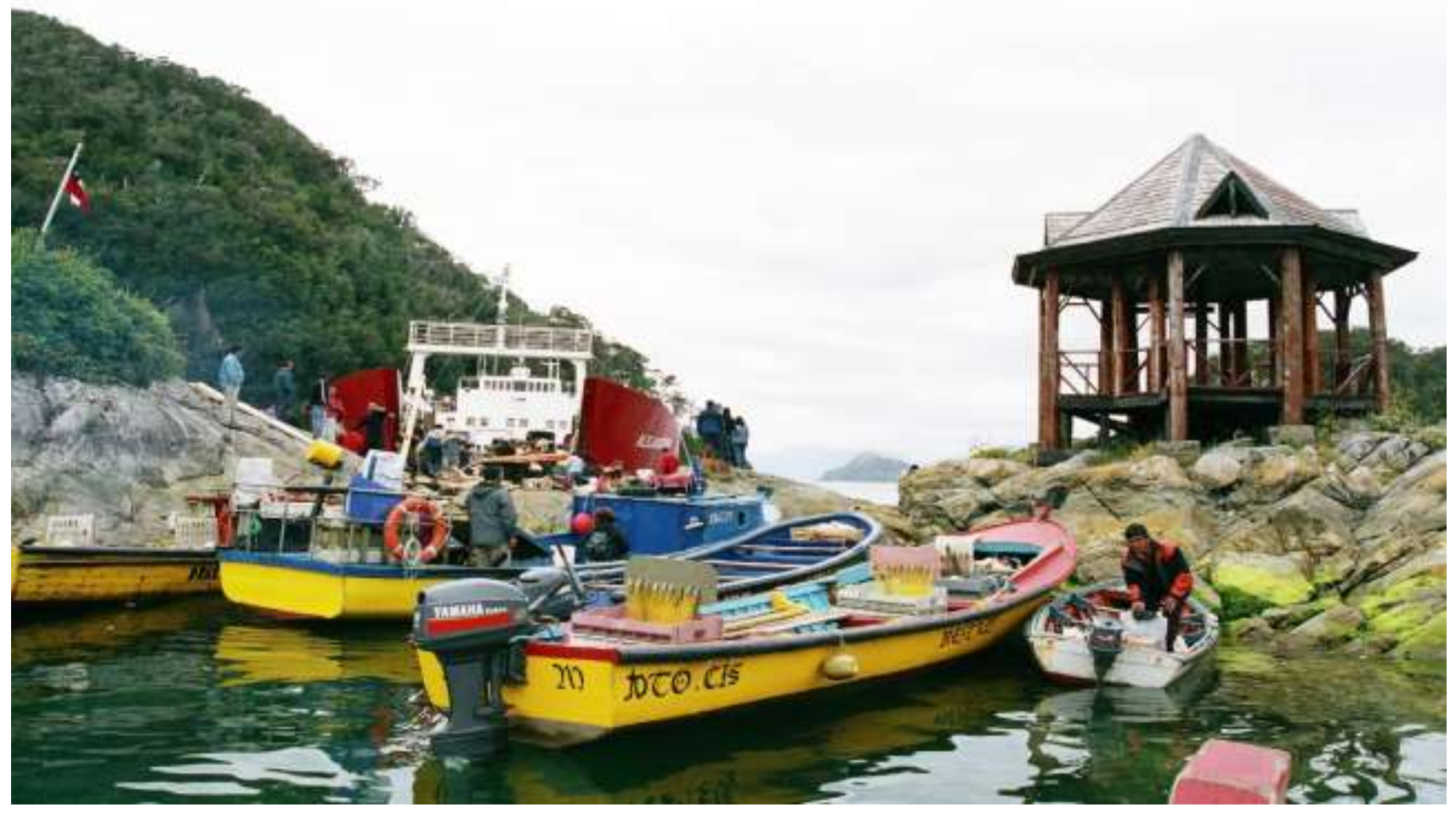

Figura 4. Embarcaciones Artesanales. Autor: Guillermo Brinck. (Brinck et al., 2011) 
Se vino gente de todo el país para acá, gente profesional, gente que vivía bien se vino: vendió sus camionetas, sus autos, su [i?], porque este era un pozo de oro aquí (el oro negro), había que venir a buscarlo no más. Pero no era tan así."

Si bien es cierto, las versiones pueden variar en la cantidad de gente que habitaba esta localidad (algunos dicen mil, otros dos mil habitantes, incluso algunos cinco mil), lo importante es reconocer la existencia de una gran masa itinerante que hoy no se encuentra en la zona, debido principalmente por la movilidad del pescador artesanal chileno, el cual recorría las costas "buscando" diferentes recursos para su extracción. Por otra parte, el progresivo decaimiento de la cantidad de merluza austral en estos canales, también es un aspecto importante a tomar en cuenta:

“Los demás [Islas Bajas, Casa de Piedra, Atilio, etc.] desaparecieron todos, la única parte que queda es esta. Por qué, porque hubo un tiempo en que la merluza se fue, y todos abandonaron, menos yo. Aquí quedamos como 40 personas porque íbamos acá y a veces salían merluzas a cuarenta millas para abajo cincuenta millas íbamos allá a pescar. Nos demorábamos como cinco horas con el motor fuera de borda. A veces nos íbamos con lanchas. Nos íbamos en ristre. Pero después volvió la merluza. Una vez estábamos pescando abajo y nos dijeron, 'no, si en Gala está saliendo más que acá.' Y ya hacen sus seis años que ya volvió. Pero ya se está notando que se está yendo la merluza, porque vienen de Aguirre a pescar acá, de Aysén igual; porque en esta zona sale la mejor merluza, mejor que en todas las otras zonas, y como salía en cantidad -porque a veces nosotros sacábamos hasta mil kilos en el día en un solo bote. Claro que no todos sacaban lo mismo, algunos hacían cien, otros doscientos."

A mediados de los años 80 y principios de los 90 la población galense gozaba de heterogeneidad de lugares de procedencia de los pescadores. La migración temporal en la búsqueda de la merluza austral, hizo que no solo en Puerto Gala, sino que en todos los alrededores de los canales Jacaf y Moraleda (Archipiélago de Chonos y las Guaitecas, incluso más al sur de Isla Magdalena) se asentaran campamentos de pesca. Estos pescadores temporales, nómadas del mar, nunca imaginaron el futuro que se avecinaba. En entrevista con Luis Llancalahuen, habitante de Paildad, Chiloe, nos señaló que en los tiempos del boom merluzero la gente nunca imaginó que se establecería un pueblo en esas islas "de paso". Siempre se pensó en la temporalidad de la estancia en esos parajes. Esta percepción no solo da muestras de la conexión ampliada que poseían estas islas, sino que también como se pensaba e imaginaba esa zona hacia esos años.

\section{Hoy por hoy: Gala en la actualidad}

Puerto Gala en el siglo XXI. Mucha agua ha pasado bajo el puente desde esos primeros años en que se asentaron los pescadores a raíz de la "fiebre de la merluza". Las ranchas de plástico temporales de los primeros asentamientos, hoy por hoy son reemplazadas por casas de metal y madera. Desde su fundación en el año 1999, se han realizado una serie de intervenciones por parte del Estado en la localidad con fin de reconocer y mejorar el estilo de vida de los habitantes. Es así que se han instalado pasarelas nuevas, las cuales conectan la mayoría de las islas de Gala; tendido eléctrico el cual funciona de 18:00hrs hasta las 00:00 hrs. de manera continua; baños para cada una de las viviendas existentes en la localidad; etc. Es innegable el hecho de que han existido avances en este sentido, pero también podemos señalar que a pesar de estos avances, aun falta mucho por hacer. Las viviendas son realmente precarias en su infraestructura. El problema del olor que emiten los baños es algo actual y que pensamos 
va a seguir en aumento. También es necesario señalar que aun en el siglo XXI los habitantes de Puerto Gala no cuentan con servicio de salud constante y presente. La importancia de esto último es de vida o muerte. Tuvimos la oportunidad de ver en terreno una persona que resultó herido con cortes de cuchillo durante una pelea. Este hombre presentaba cortes tanto en los brazos, el estómago y el cuello. Debido a su condición, tuvo que ser trasladado a Quellón para recibir asistencia médica como correspondía.

Son innegables las transformaciones que han sufrido estas islas dentro de un lapso aproximado de 30 años. Estas transformaciones van de la mano con un incipiente contacto con el sistema capitalista mayor y las dinámicas que este construye. La apertura del mercado internacional para la merluza austral, generó tanto una fuerte inmigración a la zona, como también una serie de cambios en el sentido tecnológico y socio-cultural. Hoy por hoy, podemos encontrar casas con televisión satelital, aparatos reproductores de DVD, equipos musicales con $\mathrm{CD}$, televisores pantalla plana, etc. Es decir, una gama de artículos tecnológicos que difícilmente podían ser conseguidos en el contexto en que vivían los pescadores de estas islas hace 20 años atrás.

\section{El caso de la basura en Puerto Gala. Yo, Nosotros y Ellos: Todos responsables.}

En el verano de 2007 tuve la dicha de permanecer por cerca de 25 días en Puerto Gala junto a Cristian Morales y Guillermo Brinck, antropólogos de la Universidad Academia de Humanismo Cristiano, concretando el proyecto "Vida social de la merluza austral. Economía y cultura de Puerto Gala y sus alrededores" del Núcleo de Investigación de la realidad insular de la UAHC. Los años posteriores viajamos en repetidas oportunidades, formando una relación cercana con familias y pescadores de la zona. En estas estadías, nuestro lugar de residencia fue una pequeña caleta llamada Puyuhuapi. La caleta Puyuhuapi es la que cuenta con mayor densidad poblacional del pequeño archipiélago, y por esto es que en ella en donde se encuentra la mayor cantidad de botes fondeados, en espera de su salida a la mar. Como Caleta Puyuhuapi parece un parque de estacionamiento de botes, es también en ella y en su playa en que los residuos orgánicos e inorgánicos, se hacen más visibles. El recorrido de lado a lado es de una longitud de aproximadamente 150 metros. En ella la cantidad de basura es abrumante. Envases de aceite, mezcla para motor, latas de cerveza, vidrios, bolsas plásticas, un sin fin de conchas y cabezas de pescado, trozos de madera ya ocupados, tarros de pintura, clavos, etc. La lista podría continuar si hacemos un inventario. La contaminación se hace evidente, degradando así el paisaje y además el ecosistema.

\section{El mar basurero y la isla vertedero}

El registro de trabajo de campo hace necesario las constantes incursiones en el mar y sobre la tierra. De un lado a otro, el investigador indaga y entrevista, observa y analiza, en función de los lineamientos de lo que pretende investigar. En este ir y venir constante, y en las distintas interacciones ocurridas en estos momentos del trabajo de campo, surgen algunas situaciones particulares que cabe recordar en este artículo. Un hecho que particularmente llama la atención, no solo por lo impactante que puede resultar para una persona que vive lejos del mar, sino que por lo repetitivo y diversificado que se encuentra esta práctica, es el hecho de ocupar el mar como basurero. En las faenas pesqueras, tanto de manera artesanal como industrial, se utilizan una gran variedad de insumos que corresponden principalmente al cuidado del motor de la embarcación. Es aquí donde encontramos por ejemplo botellas de 
aceite de motor, o también envases de la llamada "mezcla". Al utilizar estos insumos, el desecho, en este caso el envase plástico, es lanzado al mar fuera de borda, quedando así a la deriva, derramando el resto del componente que aún queda en el envase. Ahora bien, lo que preocupa en este caso es la expansión y extensión de su práctica. Por lo general y en la mayoría de las veces en que tuvimos la oportunidad de contemplar estas acciones típicas del pescador, el desecho es lanzado al mar, como si este se tratara de un basurero. Las consecuencias son evidentes: aquellos deshechos que no quedaban en la deriva, finalmente varaban en algún sector de la isla como pudimos vivenciar y registrar, tanto en los sectores orientales, como

también en otros sectores. Esto va generando una acumulación progresiva de basura en algunos sectores de la isla, degradando de esta manera el medioambiente y sobretodo la base de la actividad económica más importante de esta zona: el mar.

Según algunos relatos de los habitantes, años atrás se habían formado grupos de universitarios que venían a limpiar las playas y caletas. Pero, ¿Qué pasó entonces? ¿Por qué hoy en día el paisaje resulta bastante desesperanzador, si además pensamos en que el mar, medio único y base de la economía isleña, se encuentra en un proceso creciente de contaminación?

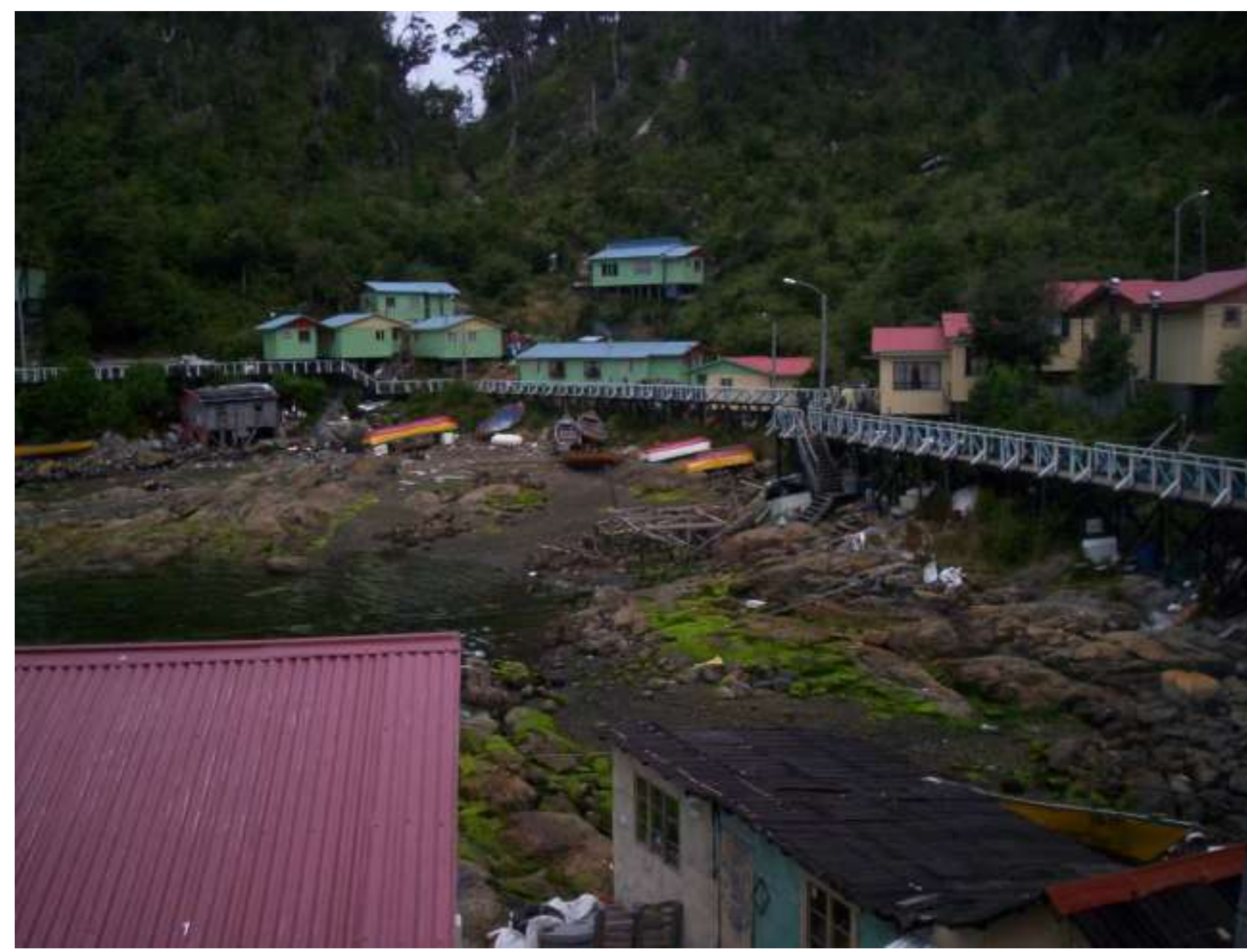

Figura 5. Caleta Puyuhuapi en Gala. Autor: Rodrigo Díaz Plá.

A 10 años de esta experiencia etnográfica, aún seguimos preguntándonos ¿Cuál será el destino socioambiental de estos parajes? 


\section{De la isla vertedero a un territorio protegido.}

Como hemos señalado anteriormente, la práctica educativa ambiental no se hace presente al menos de manera patente en Puerto Gala, cuestión que debería tener alguna repercusión en las instituciones operantes en la isla. Las islas pertenecen administrativamente a la comuna de Puerto Cisnes, por lo que la preocupación de esta administración debería estar enfocada a generar programas no solo de limpieza, sino que además de políticas educativas estables, que generen una mayor conciencia social con el tema del medio-ambiente y su deterioro a causa de la contaminación. La falta de difusión de programas de reciclaje de basura inorgánica, genera un estancamiento en el área educativa, dejando de lado un aspecto importantísimo para la salud general de la isla, del ecosistema y de las personas en particular.

La formación de un círculo de transmisión de saberes (el cómo tratar la basura, cómo manejarla, dónde desecharla, etc.) relacionados con un contacto armónico con el medioambiente mejora la calidad de vida, cuestión que definitivamente debería aspirar la especie humana.

\section{Referencias}

Alcalá, G. (1992). La ayuda mutua en las comunidades de pescadores artesanales en Mexico. Anales de Antropología (29), 179-203.

Alcalá, G., \& Camargo, A. (2012). Pescadores en América Latina y el Caribe. Espacio, población, producción y política (Primera ed.). México: UNAM.

Ascui, S. (2015). Informe final de práctica profesional: Estado de la seguridad social de los pescadores artesanales en la IV Región de Coquimbo. Santiago: Escuela de antropología, Universidad Academia de Humanismo Cristiano.

Brinck, G., y Morales, C. (2007). De la Movilidad a la Sedentarización; Procesos de Construcción del Espacio en Isla Toto/Puerto Gala. (U. d. Lagos, Ed.) Revista Labor Interdisciplinaria de Desarrollo Regional.

Brinck, G., Díaz Plá, R., Morales, C., y Marín, A. (2011). Las mutaciones de la merluza austral. Historia, etnografía y economía política en Isla Toto/Puerto Gala (Primera ed.). Santiago: Cuarto Propio.

Calderón, M., Díaz Plá, R., Morales, C., Mühle, A., Rodríguez, M., Rojas, R. y Villaseca, J. (2013). Territorios rurales y neoliberalismo en Chile. Conflictos económicos y sus expresiones políticas en zonas vitivinícolas, forestales e industrias salmonera. Cuadernos de Antropología Social(38), 153-176.

Chapanoff, M. (2001). La Invención del No Lugar: El Maritorio en la Noción de los Navegantes del Archipiélago de Chiloe. Cuarto Congreso Chileno de Antropología, (pág. 
http://rehue.csociales.uchile.cl/antropología/congreso/s0311.htm).

Diario La Epoca. (1 de Julio de 1987).

Eriksen, F. (1993). Do Cultural Island Exist? Social Anthropology (1).

Gelcich, S., Hughes, T., Olsson, P., Folke, C., Defeo, O., Fernandez, M., . . y Steneck, R. (2010). Navigating transformations in governance of Chilean marine coastal resources. . Proceedings of the National Academy of Sciences.

INE. (2008). Censo pesquero. Santiago: INE.

Luna, G. (2009). Caleta Sierra. Análisis sobre las transformaciones en la actividad pesquera artesanal. Tésis para optar al grado de Antropólogo. Santiago: Universidad Academia de Humanismo Cristiano. Escuela de Antropología.

Morales, C. (2012). Dos seres marinos - Febriles mercancías de exportación. La formación de Puerto Gala y la transformación de Apiao. Un estudio Comparado. Tesis para optar al grado de Antropólogo. Santiago: Universidad Academia de Humanismo Cristiano. Escuela de Antropología.

Morales, C., \& Calderón, M. (2010). De booms y fiebres marinas. Breve historia económica de Isla Apiao y el mercado de algas. Santiago: Consejo Regional de la Cultura y las Artes, región de Los Lagos.

SERNAPESCA. (2018). Registro Pesquero Artesanal . Coquimbo: Dirección Regional de Pesca y Acuicultura.

Stotz, W. (1997). Las áreas de Manejo en la Ley de Pesca y Acuicultura: primeras experiencias y evaluaciones de la utilidad de esta herramienta para el recurso loco. Estudios Oceanológicos, $16,67-86$.

Terrell, J. E., H, T. L., \& Gosden, C. (1997). The Dimensions of Social Life in the Pacific. Current Anthropology, 38(2), 155-195. 